\title{
Layered double hydroxide supported cobalt nanocluster: size control and the effect in catalytic hydrogen generation
}

\author{
Aishah Mahpudz ${ }^{1}$, Siu Ling Lim ${ }^{2}$,Hitoshi Inokawa $^{3 *}$,Katsuki Kusakabe ${ }^{1}$, and Ryuichi Tomoshige ${ }^{1}$ \\ ${ }^{1}$ Division of Applied Chemistry, Graduate School of Engineering, Sojo University, 4-22-1 Ikeda, Nishi-ku, Kumamoto 860-0082, Japan. \\ ${ }^{2}$ Department of Chemical Engineering, Faculty of Engineering, Universiti Teknologi PETRONAS, 32610 Seri Iskandar, Perak, Malaysia \\ ${ }^{3}$ Department of Nanoscience, Faculty of Engineering, Sojo University, 4-22-1 Ikeda, Nishi-ku, Kumamoto 860-0082, Japan.
}

\begin{abstract}
Synthesizing metal nanoclusters with diameters smaller than $5 \mathrm{~nm}$ is challenging, but desirable because of the high ratio of surface area to interior atom. However, in this report it was achieved by utilizing magnesium-aluminium layered double hydroxide $(\mathrm{Mg} / \mathrm{Al}-\mathrm{LDH})$ as a host for cobalt citrate anion precursor, which was later reduced into cobalt nanoclusters (Co-NC). Size of the Co-NC was controlled by changing the concentration of cobalt-citrate (Co-citrate) precursor during anion exchange. XRD and FTIR showed that Co-citrate precursor was successfully intercalated on the LDH while nitrogen adsorption/desorption isotherms confirmed that mesopores in the sample were formed after chemical reduction. Furthermore, TEM/STEM observations confirmed the formation of Co-NC. It was also verified that reducing the concentration of Co-citrate from $4 \mathrm{mM}$ to $0.5 \mathrm{mM}$ resulted in a reduction in the size of Co$\mathrm{NC}$ from 4.4 to $1.3 \mathrm{~nm}$. However, catalytic hydrogen generation from sodium borohydride (NaBH4) hydrolysis experiment indicated that catalytic activity decreased as the size of Co-NC decreases. This is mainly attributed to the limitation in mass transport within the interlamellar space of the smaller cluster LDH compared to the bigger one. Overall, Co-NC-LDH is a promising catalyst for NaBH4 hydrolysis. However, an optimum Co-NC size is critical for enhanced catalytic activity.
\end{abstract}

\section{Introduction}

$\mathrm{NaBH}_{4}$ is considered as an important hydrogen $\left(\mathrm{H}_{2}\right)$ storage chemical because of its high $\mathrm{H}_{2}$ storage capacity, high purity of $\mathrm{H}_{2}$ generation, and stability in alkaline solution [1]. Its hydrolysis occurs spontaneously under ambient condition according to equation described below:

$$
\mathrm{NaBH}_{4}+2 \mathrm{H}_{2} \mathrm{O} \rightarrow \mathrm{NaBO}_{2}+4 \mathrm{H}_{2}
$$

However, for aqueous $\mathrm{NaBH}_{4}$ stored in alkaline solution usage of suitable catalyst is required to enable control of the hydrolysis reaction. This is because the rate of self-hydrolysis can be almost negligible. Among various metal catalysts that have been applied to facilitate this reaction, cobalt based catalyst is a good candidate because of its high activity [2]. Furthermore, it is more economical compared to other noble metal such as $\mathrm{Pt}, \mathrm{Rh}, \mathrm{Ru}$ and $\mathrm{Pd}$ that has been previously investigated [3-5]. Nevertheless, much work is still necessary to develop Co-based catalyst that is effective as well as stable for industrial use [6].

One of the possible ways to increase activity is by reducing the size of Co-NC. This is because it is known that catalytic activity of metal nanocluster is inversely proportional to its size in certain reaction [7]. However, synthesis of small nanocluster smaller than $5 \mathrm{~nm}$ is difficult because of particle agglomeration.

To overcome this difficulty, layered double hydroxides (LDHs) have the potential to be used as a support for cobalt metal cluster due to its unique structure. LDHs are a type of anionic material that consists of positively charged layers of divalent and trivalent metals. Within the interlayer there are anion occupying the interlayer spaces that could be exchange under suitable parameters.

Overall, the objective of this work is to understand the effect of Co-NC size on its catalytic activity for $\mathrm{NaBH}_{4}$ hydrolysis in alkaline solution. In addition to that, simple method developed to obtain a tuneable size of Co-NC hosted on Mg/Al-LDH is also presented. For this method, synthesis starts with the co-precipitation of nitrate type $\left(\mathrm{NO}_{3}{ }^{-}\right)$of $\mathrm{Mg} / \mathrm{Al}-\mathrm{LDH}$ host. This is followed by anion exchange of the $\mathrm{NO}_{3}^{-}$with cobalt citrate anion (Co-citrate) and finally reduction of the co-citrate anion to $\mathrm{Co}-\mathrm{NC}$ using $\mathrm{NaBH}_{4}$. The effect of the resultant $\mathrm{Co}$ $\mathrm{NC}$ 's size on its catalytic activity was then evaluated from the generation of $\mathrm{H}_{2}$ in $\mathrm{NaBH}_{4}$ hydrolysis reaction.

\footnotetext{
* Corresponding author: inokawa@nano.sojo-u.ac.jp
} 


\section{Experiments}

\subsection{Materials}

Chemical used are; Sodium Hydroxide $(\mathrm{NaOH}$, Kanto Chemical Co., 97.0\%), Sodium Nitrate $\left(\mathrm{NaNO}_{3}\right.$, Kanto Chemical Co., 99.0\%), Magnesium Nitrate Hexahydrate $\left(\mathrm{Mg}\left(\mathrm{NO}_{3}\right)_{2} \bullet 6 \mathrm{H}_{2} \mathrm{O}\right.$, Kanto Chemical Co., 99.0\%), Aluminium Nitrate Nonahydrate $\left(\mathrm{Al}\left(\mathrm{NO}_{3}\right)_{3} \bullet 9 \mathrm{H}_{2} \mathrm{O}\right.$, Kanto Chemical Co., 98.0\%), Cobalt (II) Nitrate Hexahydrate $\left(\mathrm{Co}\left(\mathrm{NO}_{3}\right)_{2} \bullet 6 \mathrm{H}_{2} \mathrm{O}\right.$, Kanto Chemical Co., 98.0\%), Citric Acid $\left(\mathrm{C}_{6} \mathrm{H}_{8} \mathrm{O}_{7} . \mathrm{H}_{2} \mathrm{O}\right.$, Kanto Chemical Co., $99.5 \%)$, Sodium Borohydride $\left(\mathrm{NaBH}_{4}\right.$, Acros Organics, $98 \%$ ) and deionized water.

\subsection{Catalyst preparation}

\subsubsection{Synthesis of $\left(\mathrm{NO}_{3}{ }^{-}\right)-\mathrm{LDH}$}

A nitrate $\left(\mathrm{NO}_{3}{ }^{-}\right)$type of $\mathrm{Mg} / \mathrm{Al}-\mathrm{LDH}$ was synthesized by the co-precipitation method at a constant $\mathrm{pH}$ of 10 and temperature of $55^{\circ} \mathrm{C}$. In a typical procedure, two $100 \mathrm{ml}$ aqueous solutions were prepared. Solution A contained $0.5 \mathrm{M}$ of mixed salt solution of $\mathrm{Mg}\left(\mathrm{NO}_{3}\right)_{2} \bullet 6 \mathrm{H}_{2} \mathrm{O}$ and $\mathrm{Al}$ $\left(\mathrm{NO}_{3}\right)_{3} \cdot 9 \mathrm{H}_{2} \mathrm{O}$ (molar ratio of $2: 1$ ) while solution $\mathrm{B}$ was $2 \mathrm{M}$ of $\mathrm{NaOH}$. Both solutions were simultaneously added into a reaction vessel containing $250 \mathrm{ml}$ of $1 \mathrm{M} \mathrm{NaNO}$ under vigorous stirring. Solution $\mathrm{A}$ was added at a rate of $1 \mathrm{ml} / \mathrm{min}$ while the addition of solution B was at an appropriate rate that ensures the $\mathrm{pH}$ variation does not exceed \pm 0.1 of the target $\mathrm{pH}$ value. Once the addition of solution A was completed, the resulting slurry were continuously stirred for another 30 minutes and then it was filtered, rinsed with deionized water, and dried at $100{ }^{\circ} \mathrm{C}$ overnight.

It is important to note that for the purpose of catalyst preparation, dissolved gasses in the used deionized water were removed first using vacuum pump aspirator. Also, the synthesis was conducted in an inert atmosphere where $\mathrm{N}_{2}$ gas was flowed continuously into the reaction vessel. These steps were taken to prevent carbonate $\left(\mathrm{CO}_{3}{ }^{2-}\right)$ contamination in the synthesized product.

\subsubsection{Synthesis of (Co-citrate)-LDH}

In this anion-exchange, the $\mathrm{NO}_{3}{ }^{-}$in the interlayer of the LDH host was replaced with Cobalt citrate anion (Cocitrate). For this, a $300 \mathrm{ml}$ solution containing equimolar ratio of $\mathrm{Co}\left(\mathrm{NO}_{3}\right)_{2} \bullet 6 \mathrm{H}_{2} \mathrm{O}$ and citric acid were prepared in a flask and placed on a water bath of temperature $50{ }^{\circ} \mathrm{C}$. Prior to adding $1.0 \mathrm{~g}$ of dried $\left(\mathrm{NO}_{3}{ }^{-}\right)-\mathrm{LDH}, \mathrm{pH}$ of the solution were increased to 9.5 by adding $0.1 \mathrm{M} \mathrm{NaOH}$ and the suspension was magnetically stirred for 12 hours. Subsequently, it was filtered and rinsed with deionized water. Half of the solid residue was dried at $100{ }^{\circ} \mathrm{C}$ and utilized for characterization while the remainder was immediately reduced with sodium borohydride $\left(\mathrm{NaBH}_{4}\right)$ (described in the following section). This anion-exchange was repeated with various concentration of Co-citrate solution namely 4, 2, 1 and $0.5 \mathrm{mM}$.

\subsubsection{Chemical reduction with $\mathrm{NaBH}_{4}$}

During chemical reduction, the Co-citrate anion in the interlayer of $\mathrm{LDH}$ was reduced to Co-NC. For this, the wet (Co-citrate-)-LDH was dispersed in $50 \mathrm{ml}$ solution containing $5 \mathrm{~g}$ of $\mathrm{NaBH}_{4}$ at $50{ }^{\circ} \mathrm{C}$ for 2 hours. Then, the solid residue was retrieved by filtration, rinsed with deionized water, and dried overnight at $100{ }^{\circ} \mathrm{C}$. These reduced samples are denoted as $x \mathrm{mM}$ Co-LDH where $\mathrm{x}$ $=4,2,1$ or 0.5 . Summary of the three-step procedure used to synthesize the samples is shown on Fig. 1.

\subsection{Characterization}

Crystal structure was characterized by X-ray Diffraction (XRD, Rigaku Smartlab) using $\mathrm{Cu} \mathrm{K \alpha}$ irradiation (1 = $0.1540562 \mathrm{~nm}$ ) at $40 \mathrm{kV}$ and $30 \mathrm{~mA}$ for the $2 \theta$ value ranging from of $5^{\circ}-90^{\circ}$ at a scan rate of $2 \% \mathrm{~min}$. The textural properties such as BET surface area were obtained from $\mathrm{N}_{2}$ sorption isotherms obtained at -195.8 ${ }^{\circ} \mathrm{C}$ under continuous adsorption conditions using surface area and porosity analyser (Micromeritis TriStar II, Japan). The samples were degassed at $200{ }^{\circ} \mathrm{C}$ for $15 \mathrm{~h}$ prior to measurements. Elemental analysis was done using Scanning Electron Microscopy coupled with Energy Dispersive X-Ray Spectroscopy (SEM and EDS, Elionix ERA-600). Fourier transform infrared (FTIR, Perkin Elmer Spectrum 100) analysis was done within the range of $4000-650 \mathrm{~cm}^{-1}$. Weight $\%$ of Co in the LDH was identified by Inductively Coupled Plasma-Optical Emission Spectrometry (ICP-OES) where the sample was prepared by dissolving $10 \mathrm{mg}$ of the sample in $0.1 \mathrm{M}$ nitric acid before analysis. Transmission electron microscope (TEM, FEI Titan Themis) was used to observe the structure of catalyst as well as measure the size of Co-NC.

\subsection{Hydrogen Generation Rate (HGR) from catalytic hydrolysis of $\mathrm{NaBH}_{4}$}

Catalytic activity was evaluated by the hydrolysis of $\mathrm{NaBH}_{4}$ generating $\mathrm{H}_{2}$ using the water displacement method similar to previous research $[8,9]$. Typically, an aqueous solution containing 5 mass $\%$ of $\mathrm{NaBH}_{4}$ and 5 mass $\%$ of $\mathrm{NaOH}$ with a total mass of $10 \mathrm{~g}$ were prepared in a flask and then placed in a water bath at $25^{\circ} \mathrm{C}$. The hydrolysis reaction was initiated by adding $0.05 \mathrm{~g}$ of the $x \mathrm{mM}$ Co-LDH into the solution. Once initiated, the volume of water displaced by $\mathrm{H}_{2}$ gas from a water tank into a mass balance was recorded over time. The Hydrogen Generation Rate (HGR) was calculated to evaluate the catalytic activity. 


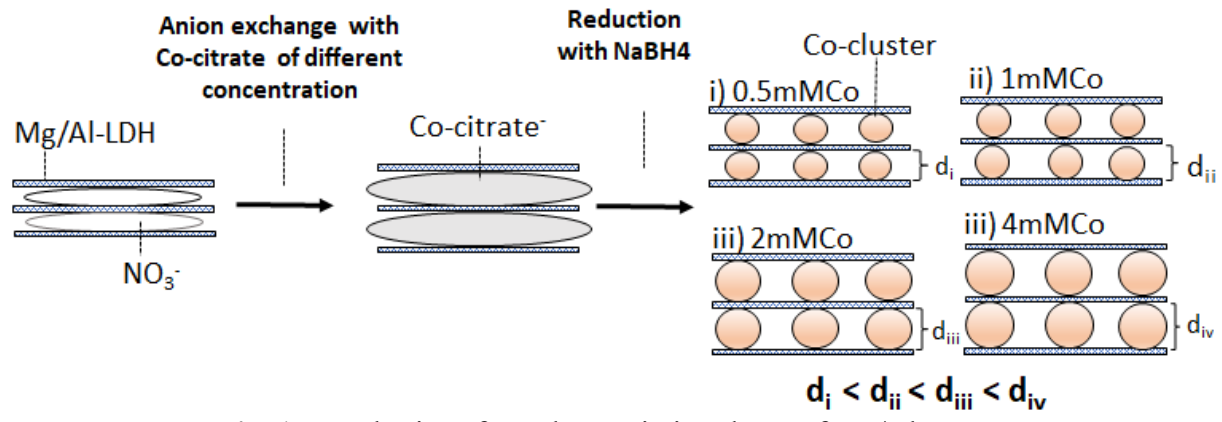

Fig. 1. Synthesize of Co clusters in interlayer of $\mathrm{Mg} / \mathrm{Al}-\mathrm{LDH}$
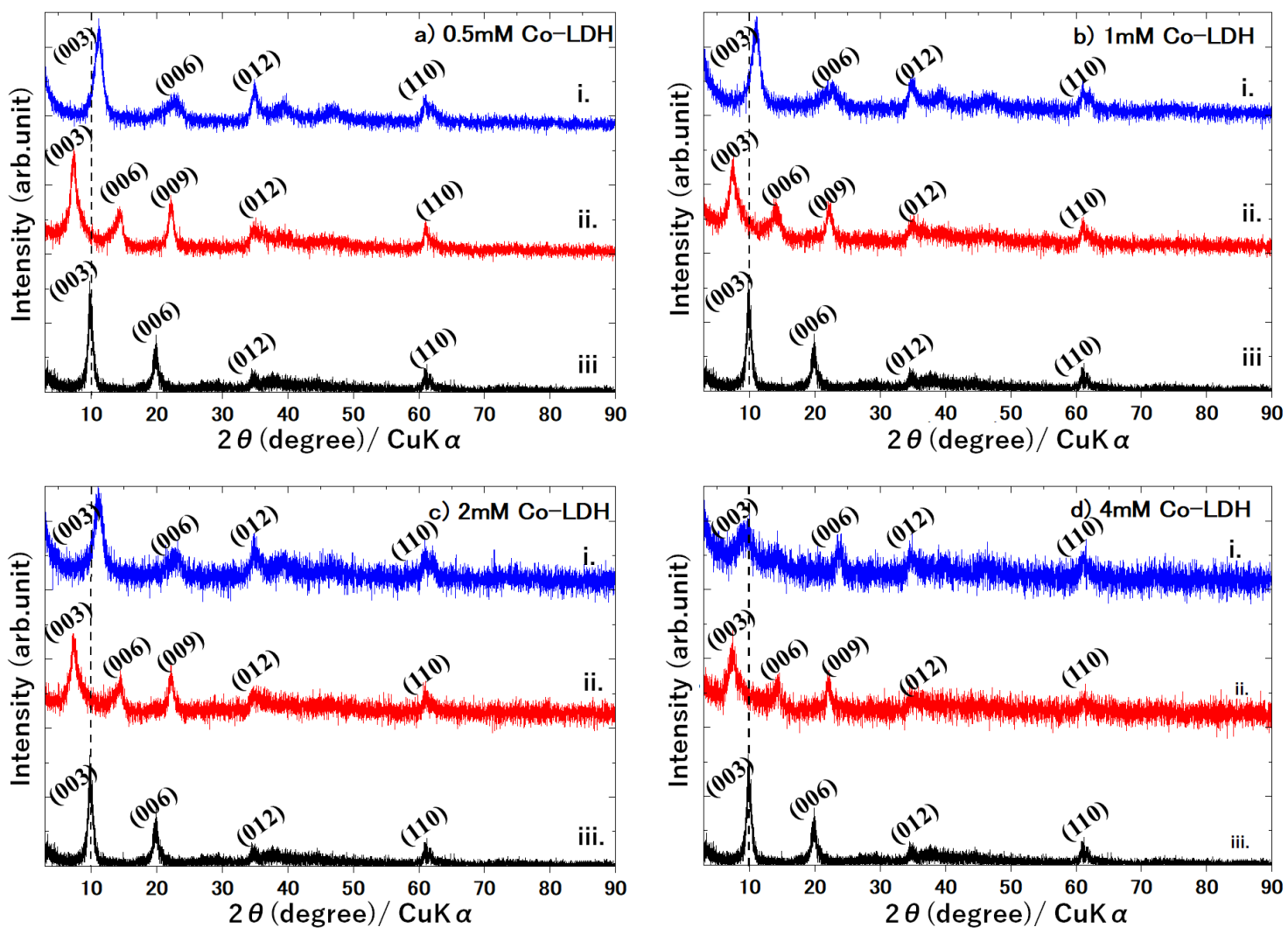

Fig. 2. XRD of samples synthesized from anion exchange of a) $0.5 \mathrm{mM}$, b) $1 \mathrm{mM}$, c) $2 \mathrm{mM}$ and d) $4 \mathrm{mM}$ Co-citrate solution. Each peak corresponds to, i) as-synthesized $\left(\mathrm{NO}_{3}{ }^{-}\right)-\mathrm{LDH}$, ii) (Co-citrate-)-LDH (after anion exchange) and iii) $x \mathrm{mM} \mathrm{Co-LDH}$
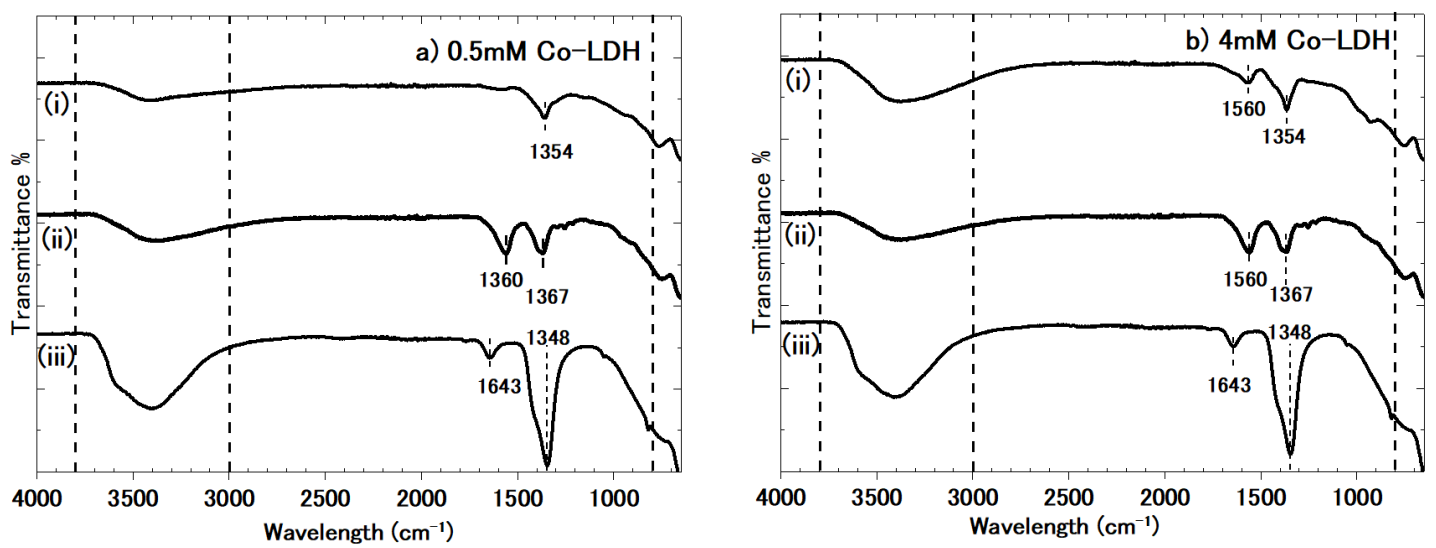

Fig. 3. FTIR of samples synthesized from anion exchange of a) $0.5 \mathrm{mM}$ and b) $4 \mathrm{mM}$ Co-citrate solution. Each peak corresponds to, i) as-synthesized $\left(\mathrm{NO}_{3}^{-}\right)-\mathrm{LDH}$, ii) (Co-citrate-)-LDH (after anion exchange) and iii) $x \mathrm{mM} \mathrm{Co-LDH}$ 


\section{Results and discussion}

\subsection{Characterization}

XRD peaks of all the sample are displayed in Fig. 2. For the $\left(\mathrm{NO}_{3}^{-}\right)-\mathrm{LDH}$ as shown in Figure 2a-d i), the peaks (0 $\left.\begin{array}{ll}0 & 3\end{array}\right),\left(\begin{array}{lll}0 & 0 & 6\end{array}\right),\left(\begin{array}{lll}0 & 1 & 2\end{array}\right)$ and $\left(\begin{array}{lll}1 & 1 & 0\end{array}\right)$ appearing is characteristic of LDH materials $[10,11]$. The peak $(00$ 3) appearing at $2 \theta=10^{\circ}$ corresponds to a basal spacing $\mathrm{d}_{(003)}$ of $0.88 \mathrm{~nm}$ when calculated from Bragg's equation. This value is in good agreement with the $\mathrm{d}_{(003)}$ of $\mathrm{a} \mathrm{NO}_{3}$ ? type of $\mathrm{Mg} / \mathrm{Al}-\mathrm{LDH}$ as reported in literature [12].

Compared to the $\left(\mathrm{NO}_{3}^{-}\right)-\mathrm{LDH}$, after anion exchange a general trend is observed on all four cases where the peak $\left(\begin{array}{lll}0 & 0 & 3\end{array}\right)$ and $\left(\begin{array}{lll}0 & 0 & 6\end{array}\right)$ shifted to a lower $2 \theta$ angle which indicates an increase in basal spacing. For example, the peak $\left(\begin{array}{lll}0 & 0 & 3\end{array}\right)$ of the $0.5 \mathrm{mM}$ Co-citrate-LDH sample shifted to $7.3^{\circ}$ and the calculated $\mathrm{d}_{(003)}$ is 1.21 $\mathrm{nm}$. This result implies successful intercalation of cocitrate anion which causes an expansion in the LDH interlayer to accommodate the larger citrate anion.

On the other hand, after reduction with $\mathrm{NaBH}_{4}$ the XRD pattern of the $0.5 \mathrm{mM}$ Co-LDH shows that the peak $\left(\begin{array}{lll}0 & 0 & 3\end{array}\right)$ shifted to $11.5^{\circ}$ in which the corresponding $d_{(003)}$ is reduced to $0.77 \mathrm{~nm}$. This shrinkage in gallery height resembles the basal spacing of LDH intercalated with carbonate anion $\left(\mathrm{CO}_{3}{ }^{2-}\right)[12]$. The presence of $\mathrm{CO}_{3}{ }^{2-}$ species in the reaction environment may originate from the organic ligand of the complex anion which decomposes into various gaseous hydrocarbons during reduction $[9,13]$. Considering the high affinity of $\mathrm{CO}_{3}{ }^{2-}$ with the LDH framework it could easily intercalated to restore the anion in the interlayer of LDH.

Furthermore, the peaks of $x \mathrm{mM}$ Co-LDHs also confirms that the Mg/Al-LDH host was not also reduced during the process. This is because the peak position remained unchanged and no new peak appears indicating structural integrity. Except for the $4 \mathrm{mM}$ Co-LDH sample however, reduced crystallinity and the broadening of the peak $\left(\begin{array}{lll}0 & 0 & 3\end{array}\right)$ can be observed. This may be attributed to disruption in the stacking sequence of the brucite-like layers along the c-axis [14]. Also, the possibility of some citrate anion still present after reduction may cause the broadening. Citrate anion has shown to have high affinity towards water molecule instead of the hydroxyl groups of the metal hydroxide layer. This preference results in some hydration and swelling of interlayer of LDH and hence broadening on the peak shown in XRD $[13,15]$

It should be noted that for all four of the $x \mathrm{mM} \mathrm{Co-}$ $\mathrm{LDH}$, the diffraction peak related to cobalt-phase is not present. This is because of the low loading of cobalt as well as the irregularities in the size of the synthesized Co-NC within the interlayer of the LDH.

FTIR spectra of sample synthesized using $0.5 \mathrm{mM}$ Co-citrate solution are shown in Fig. 3 a). The $\left(\mathrm{NO}_{3}^{-}\right)$LDH shown in i) displays bands characteristics of hydrotalcite-type compound which are similar to previously reported studies $[16,17]$. The broad maxima in the range between 3000 and $3800 \mathrm{~cm}^{-1}$ arises because of the $\mathrm{OH}$ stretching vibration of the hydroxyl group in the brucite-like layer $[18,19]$. A weak band observed at around $1643 \mathrm{~cm}^{-1}$ is a result of the angular bending of interlayer and absorbed water molecule [16]. While the strong absorption band at $1348 \mathrm{~cm}^{-1}$ is attributed to the stretching vibration of $\mathrm{NO}_{3}^{-}$[20]. Toward the lower frequency, bands appearing below $800 \mathrm{~cm}^{-1}$ are ascribed to the vibration of metal with oxygen bond ( $\mathrm{Mg}-\mathrm{O}$ and Al-OH stretching absorption) [13, 21].

Similarly, the $\mathrm{OH}$ stretching vibration can still be observed after intercalation and reduction of the sample. However, compared to the $\left(\mathrm{NO}_{3}^{-}\right)-\mathrm{LDH}$ a characteristic absorption of the carboxylate group originated from the citrate ligands can be observed in the (Co-citrate-)-LDH sample shown in Fig.3 a ii). The distinct vibration peak at $1560 \mathrm{~cm}^{-1}$ and $1367 \mathrm{~cm}^{-1}$ is related to the asymmetric $v_{\text {as }}\left(-\mathrm{COO}^{-}\right)$and symmetric $\mathrm{v}_{\mathrm{s}}\left(-\mathrm{COO}^{-}\right)$respectively [13]. Therefore, this indicates that the $\mathrm{NO}_{3}^{-}$in the interlayer has been removed and replaced with citrate complex anion.

On the other hand, the disappearance of the citrate ligands adsorption in the $0.5 \mathrm{mM}$ Co-LDH sample shown in Fig.3 a-iii) confirms its decomposition during reduction. Additionally, a peak appearing at around 1354 $\mathrm{cm}^{-1}$ which is close to $\mathrm{CO}_{3}{ }^{2-}$ vibration of $\mathrm{LDH}$ material can be observed $[22,23]$. This implies that while the Cocitrate anion was being reduced to $\mathrm{Co}-\mathrm{NC}$, it was replaced with $\mathrm{CO}_{3}{ }^{2-}$ anion to restore the charge balance of the resulting $0.5 \mathrm{mM} \mathrm{Co-LDH}$.

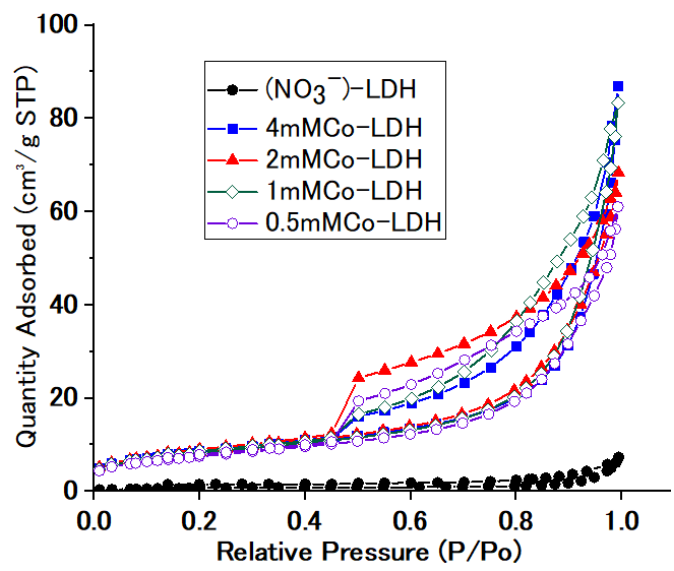

Fig. 4: $\mathrm{N}_{2}$ adsorption-desorption isotherms of $\left(\mathrm{NO}_{3}{ }^{-}\right)-\mathrm{LDH}$ and the samples after reduction with $\mathrm{NaBH}_{4}$

Table 1: Summary of BET and Pore volume of $\left(\mathrm{NO}_{3}{ }^{-}\right)-\mathrm{LDH}$ and the samples after reduction with $\mathrm{NaBH}_{4}$

\begin{tabular}{|c|c|c|}
\hline $\begin{array}{c}\text { Sample } \\
\text {-LDH }\end{array}$ & $\begin{array}{c}\text { BET } \\
\text { Surface } \\
\text { Area } \mathbf{~ m}^{2} / \mathbf{g}\end{array}$ & $\begin{array}{c}\text { Pore } \\
\text { Volume } \\
\left(\mathbf{c m}^{3} / \mathbf{g}\right)\end{array}$ \\
\hline$\left(\mathrm{NO}_{3}{ }^{-}\right)$ & 2.4 & 0.007 \\
\hline $4 \mathrm{mM} \mathrm{Co}$ & 27.0 & 0.074 \\
\hline $2 \mathrm{mM} \mathrm{Co}$ & 29.3 & 0.099 \\
\hline $1 \mathrm{mM} \mathrm{Co}$ & 30.6 & 0.085 \\
\hline $0.5 \mathrm{mM} \mathrm{Co}$ & 30.0 & 0.092 \\
\hline
\end{tabular}




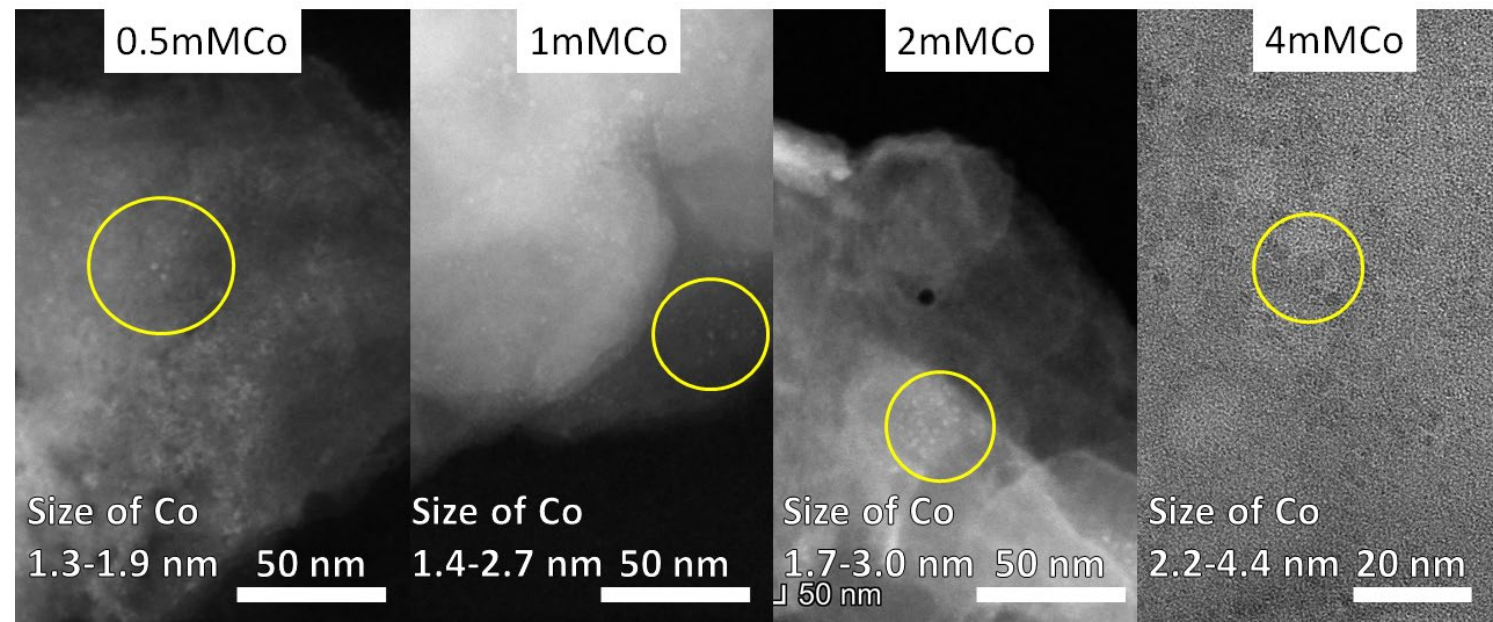

Fig. 5. TEM/STEM images of $0.5 \mathrm{mM} \mathrm{Co}, 1 \mathrm{mM} \mathrm{Co}, 2 \mathrm{mM}$ Co, $4 \mathrm{mM}$ Co-LDH

Similar trend is observed in the FTIR spectra of the other two samples of 1 and $2 \mathrm{mM}$ Co-LDH (not shown here) except for the 4mM Co-LDH (shown in Fig. 3 biii). For this sample, small absorption band at $1560 \mathrm{~cm}^{-1}$ remained. This indicates that a small amount of the citrate ligand may have not been completely reduced. Regardless, these FTIR observation is in good agreement with the previously shown XRD results

Results shown so far indicates successful intercalation of the Co-citrate anion in the interlayer of $\mathrm{LDH}$ as well as successful reduction of the citrate ligands. However, in order to confirm the formation of Co-NC it is important to understand the changes in the material's surface properties that may arise from its formation. Hence, $\mathrm{N}_{2}$ adsorption/desorption analysis was conducted, and Figure 4 shows the corresponding $\mathrm{N}_{2}$ adsorption isotherm. The $\left(\mathrm{NO}_{3}{ }^{-}\right)-\mathrm{LDH}$ shows a type II adsorption isotherm (IUPAC classification) that is typical of a non-porous structure. After reduction all 4 samples shows a type IV adsorption isotherm with H3type hysteresis loop which is characteristic of a mesoporous structure [24]

Furthermore, the BET surface area and pore volume obtained for all four reduced samples are summarized in Table 1. Compared to the $\left(\mathrm{NO}_{3}{ }^{-}\right)-\mathrm{LDH}$, all four of the reduced samples show a significant increment in BET surface area and pore volume. Specifically, the presence of mesopores in an otherwise non-porous structure indicates the formation of $\mathrm{Co}-\mathrm{NC}$ in the interlayer after chemical reduction.

TEM/STEM observations were employed to further confirm the formation of Co-NC on the LDH host. Each circle in Fig. 5 highlights the visible dots on the TEM images of the $0.5 \mathrm{mM} \mathrm{Co}, 1 \mathrm{mM} \mathrm{Co}, 2 \mathrm{mM} \mathrm{Co}, 4 \mathrm{mM}$ CoLDH samples. These dots are identified as the Co-NC that was formed after reduction with $\mathrm{NaBH}_{4}$. Measurements of Co-NC size from TEM images also suggest the facts that; The sample prepared from a lower concentration of Co-citrate solution during anion exchange has a smaller range of Co-NC size deposited compared to the one prepared from a higher concentration. This is because when the concentration of Co-citrate anion is higher, more can be intercalated on the LDH during anion exchange. Following that, due to the higher amount of Co-citrate anion present during reduction the Co-NC could agglomerate into larger cluster.

Nevertheless, this result is evident that the size of Co-NC deposited could be tuned by changing concentration of Co-citrate solution in the anion exchange step.

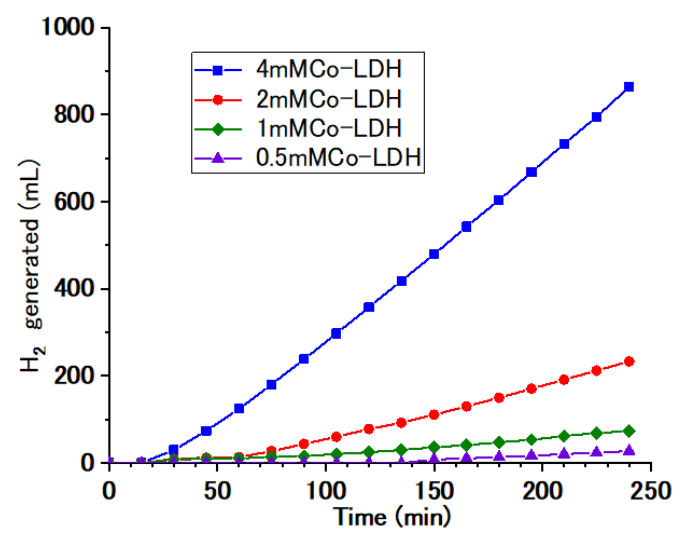

Fig. 6 Quantity of $\mathrm{H}_{2}$ gas generated over time for the $0.5 \mathrm{mM} \mathrm{Co}, 2 \mathrm{mM}$ Co, $1 \mathrm{mM}$ Co and $4 \mathrm{mM} \mathrm{Co}-\mathrm{LDH}$

Table 2. Summary of Co loading from ICP-OES, b) Co-NC size from TEM/ STEM, and c) Hydrogen Generation Rate (HGR)

\begin{tabular}{|c|c|c|c|}
\hline $\begin{array}{c}\text { Sample- } \\
\text { LDH }\end{array}$ & $\begin{array}{c}\text { a) } \\
(\mathrm{Wt} \% \mathrm{Co})\end{array}$ & $\begin{array}{c}\text { b) Co- } \\
\text { NC size } \\
\text { (nm) }\end{array}$ & $\begin{array}{l}\text { c) } \mathrm{HGR} \\
\left(\mathrm{mol}_{\mathrm{H} 2} \cdot \mathrm{s}^{-1}\right. \\
\left.\mathrm{mol}_{\mathrm{Co}}{ }^{-1}\right)\end{array}$ \\
\hline $4 \mathrm{mM} \mathrm{Co}$ & 5.7 & $2.2-4.4$ & 0.060 \\
\hline $2 \mathrm{mM} \mathrm{Co}$ & 2.3 & $1.7-3.0$ & 0.047 \\
\hline $1 \mathrm{mM} \mathrm{Co}$ & 1.8 & $1.4-2.8$ & 0.018 \\
\hline $0.5 \mathrm{mM} \mathrm{Co}$ & 1.1 & 1.3-1.9 & 0.015 \\
\hline
\end{tabular}




\subsection{Catalytic $\mathrm{H}_{2}$ generation}

Catalytic activity of the $x \mathrm{mM}$ Co-LDH samples were evaluated from the generation of $\mathrm{H}_{2}$ during hydrolysis of $\mathrm{NaBH}_{4}$ in alkaline condition. The cumulative volume of $\mathrm{H}_{2}$ generated over time in the experiment are shown in Fig. 6. After 240 mins, the $4 \mathrm{mM}$ Co-LDH sample has the highest $\mathrm{H}_{2}$ generated at $4.3 \mathrm{ml} . \mathrm{min}^{-1}$. This is followed by the $2 \mathrm{mM} \mathrm{Co}, 1 \mathrm{mM}$ Co and $0.5 \mathrm{~mm}$ Co-LDH with $\mathrm{H}_{2}$ generation of $1.4,0.4$ and $0.2 \mathrm{ml} \cdot \mathrm{min}^{-1}$ respectively.

Regardless, ICP-OES analysis was conducted to quantify the weight $\%$ of Co loaded on the LDH where the results are summarized in Table 2 a). Also, based on the Co loading, the HGR was calculated (summarized on Table 2c). From the table, it can be observed that the $4 \mathrm{mMCo}-\mathrm{LDH}$ has the highest HGR followed by $2 \mathrm{mM}$ Co, $1 \mathrm{mM} \mathrm{Co}$ and $0.5 \mathrm{~mm}$ Co-LDH. This confirms that smaller $\mathrm{Co}-\mathrm{NC}$ has lower catalytic activity compared to the larger one.

Although this observation is opposite from the initial expectation, it can be elucidated by the difficulty in mass-transport of reactant/product to/from the Co active site. For smaller cluster size, the interlamellar distance is narrow, hence limiting the access to the active sites. In addition to this, deposition of a colourless precipitate of $\mathrm{NaBO}_{2}$ which is the by-product of $\mathrm{NaBH}_{4}$ hydrolysis could cause clogging within the interlamellar space. This may then significantly reduce the efficiency of the system by which further adsorption and desorption of the reactants and/or products on the Co active site is hindered [25]. Also, another possible reason is changes in the morphology during reaction. Referring again to Fig. 6, it is shown that, upon the addition of catalyst, $\mathrm{H}_{2}$ was not immediately generated. After a certain amount of time depending on the catalyst, generation of $\mathrm{H}_{2}$ starts and accumulate over time. During this time, it is possible the Co-NC are being reduced in-situ by $\mathrm{NaBH}_{4}$ and the catalyst morphology may evolve [26].

Moreover, this could also be ascribed to the difference in crystallinity of the various sizes of Co-NC. Generally, there is a correlation between the size of metal nanoparticles with its crystallinity. Difference in crystallinity could indicate variation in the percentages of different crystal facets and defects which may influence the catalytic activity [27].

\section{Conclusion}

In summary, varying the concentration of Co-citrate solution during anion exchange is an effective way to control the size of Co-NC deposited on LDH support. However, the $x \mathrm{mM}$ Co-LDH with smaller Co-NC has lower catalytic activity compared to sample with bigger Co-NC. This is mainly because of limitations in mass transport of product and/or reactant to the active site as well as the possibility of difference in the crystallinity of the metal NP. Nevertheless, this outcome shows that it has a promising catalytic application, but a threshold Co cluster size is necessary for maximum efficiency.

\section{References}

1. B.H. Liu, and Z.P. Li, J. Power Sources, 187, 2, p. 527-534 (2009)

2. P. Brack, Dann S.E., and K.G. Upul Wijayantha, Energy Sci Eng, 3, 3, p. 174-188 (2015).

3. A. Uzundurukan, and Y. Devrim, Int. J. Hydrogen Energy, 44, 33 (2019)

4. S. Akbayrak, Z. Özçifçi, and A. Tabak, J.Colloid Interface Sci, 546: p. 324-332 (2019)

5. C.Wu, J. Guo, J. Zhang, et al., Renew Energy, 136, p. 1064-1070. (2019)

6. D. Xu, X. Zhang, X. Zhao, et al., Int. J. Energy Res, 43, 8, p. 3702-3710 (2019)

7. M. Haruta. Catal Today, 36, 1, p.153-166. (1997)

8. Y. Huang, Y. Wang, R. Zhao, et al., Int. J. Hydrog Energy, 33, 23, p. 7110-7115 (2008)

9. H. Inokawa, H. Driss, F. Trovela, et al., Int. J. of Energy Res, 40, 15 p. 2078-2090 (2016)

10. Z.P. Xu and H.C. Zeng, J. Phys Chem B , 105, 9, p. 1743-1749 (2001)

11. S. J. Xia, F. X. Liu, Z. M. Ni, et al., J. Colloid Interface Sci, 405, p. 195-200 (2013)

12. S. Miyata, Clays Clay Miner, 31, 4, p. 305-311, (1983)

13. D.A. Islam, D. Borah, and H. Acharya, RSC Adv., 5, 17, p. 13239-13245 (2015)

14. C. Gérardin, D. Kostadinova, B. Coq, et al., Chem. Mater., 20(6), p. 2086-2094 (2008)

15. Q. Li, and R.J. Kirkpatrick, Am. Mineral., 92, 2-3, p. 397-402 (2007)

16. P. Kuśtrowski, D. Sułkowska, L. Chmielarz, et al., Microporous and Mesoporous Mater., 78, 1, p. 11$22(2005)$

17. M.D. Ureña-Amate, N.D. Boutarbouch, M. SociasViciana, et al., Appl Clay Sci., 52, 4, p. 368-373 (2011)

18. J.T. Kloprogge and R.L. Frost, J. Solid State Chem, 146, 2, p. 506-515 (1999)

19. R. Lahkale, W. Elhatimi, R. Sadik, et al., Appl Clay Sci., 158: p. 55-(2018).

20. Coates, J., Interpretation of Infrared Spectra, A Practical Approach, in Encyclopedia of Analytical Chemistry.

21. J.C. Villegas, O. H. Giraldo, K. Laubernds, et al., Inorg. Chem, 42, 18, p. 5621-5631 (2003)

22. N. Iyi, T. Matsumoto, Y. Kaneko, et al., Chem. Lett., 33, 9, p. 1122-1123. (2004)

23. S. Kumar, M. A. Isaacs, R. Trofimovaite, et al., Appl. Catal. B: Environmental, 209, p. 394-404 (2017)

24. M. Thommes, K. Kaneko, A.V. Neimark, et al., Pure and Applied Chemistry, 87, 9-10, p. 1051-1069 (2015)

25. Z. Gao, C. Ding, J. Wang, et al., Int. J. Hydrogen Energy, 2019. 44, 16, p. 8365-8375 (2019)

26. U.B Demirci and P. Miele, Phys Chem Chem Phys, 16, 15, p. 6872-6885 (2014)

27. P. Liu, X. Gu, K. Kang, et al., ACS Appl Mater Interfaces, 9, 12, p. 10759-10767 (2017) 